\title{
Art, Scholarship, Community: Experiences of Viewing
}

\author{
Alice Eden* \\ History of Art Department, University of Warwick \\ *Correspondence: a.a.eden@warwick.ac.uk
}

\begin{abstract}
This critical reflection piece originated in a visit to the 'Artists and Academics' exhibition held at Fargo Creative Village, Coventry, 26 November 2016. My thoughts about the exhibition have served as a springboard to consider ideas of scholarship, art and community more broadly. I use my research on British artists from the early twentieth century, their ideas about the processes of viewing art and the spiritual in art, to discuss examples in the exhibition. I conclude by considering how this collaborative event can bring academic ideas into conversation with artworks. I suggest that the resulting exchanges may enable viewers to think differently about art and scholarship as well as enrich academic practise.
\end{abstract}

Keywords: art, community, viewing, collaboration, inter-disciplinarity, public engagement, spirituality, emotion

Funding: See page 241

Peer review: This article has been subject to a double blind peer review process

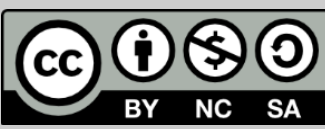

(C) Copyright: The Authors. This article is issued under the terms of the Creative Commons Attribution NonCommercial Share Alike License, which permits use and redistribution of the work provided that the original author and source are credited, the work is not used for commercial purposes and that any derivative works are made available under the same license terms.

\section{Introduction}

My research has focussed on three 'forgotten' British artists, all of whom were very much concerned with the relationships between art and the public. I I will begin with an academic overview of their ideas about art for the public and the processes that might occur during the viewing of artworks. I will then present a review of the 'Artists and Academics' exhibition held at Fargo Creative Village, Coventry in November 2016 considered in relation to these ideas. The exhibition was the result of collaborations between artists and academics; my visit was also collaborative, with an artist. This article has sought to combine the scholarly with the personal in a review of the exhibition based on informal discussions. The article may be viewed as another type of collaboration. During the process of this critical reflection, I consider the benefits of these types of approaches, which bring together different perspectives. 


\section{Viewing Art}

Robert Anning Bell, Thomas Cooper Gotch and Frederick Cayley Robinson all worked in Britain from the 1880 s to the 1930s. Amidst tumultuous changes in technology, transport, urban life heralding modernity, these artists maintained a persistent interest in Pre-Raphaelitism and figurative, imaginative compositions. In the early twentieth century, this focus made them unfashionable, they became neglected in reviews and art criticism whilst Modernism reshaped the face of the artworld. The reputations of these artists continue to languish today, though scholarly interest has slowly increased since the 1980s (1989). The 'New Modernist Studies' currently seeks to explore other unfamiliar figures in the cultural history of modernity in Britain. "ii My thesis has contributed substantial new material on the three artists in an effort to restore them to the narratives of art history and thus re-shape our understanding of modern Britain.

These artists considered the role of art for the public. Robert Anning Bell contributed to articles in The Times, for example in 1921, where he urged artists to 'take art to the public' (1921: 11). Anning Bell believed in the value of decorative commissions in cities and public areas, such as mosaic and brightly painted relief decoration on buildings, completing many such works himself (2012). The artist held a variety of views with regard to the uplifting and joyful effect of art in cities, which were drawn from his allegiances to the Arts and Crafts movement as well as older nineteenth-century ideas about the educational value of art (1987). Though inspired by socialistic ideology, Anning Bell's approach to art and the public was practical, forged through conscientious artistic practise. The artist believed that the integrity of method and materials would impart an edifying and uplifting effect on the viewer. In this way, art could become an ethical and moral project (1904).

Thomas Cooper Gotch gave lectures in the early twentieth century which considered at length the value of the audience in helping to make the

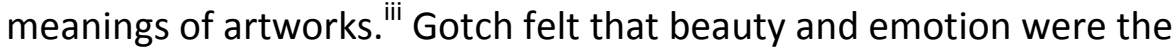
most powerful bonds which connect the audience with an artwork and these should be fostered as far as possible through sincere, virtuous art subjects. One of Gotch's most successful works was The Child Enthroned, (1894, Untraced, Private Collection), an idealised portrait of his daughter seated on a richly decorated throne. The picture was immediately strange to viewers as it did not represent any precise historic example. Instead, Gotch used an undetermined iconic image to impart a message about hope and possibility through sanctified girlhood. Gotch believed that paintings should be refined into such frozen icons that captivate through heightened emotional connection. This mystical idea of art was practised by Symbolist artists across Europe, where exact meaning was 
downplayed in favour of a transcendent connection in the viewing of art works (2009).

Frederick Cayley Robinson created murals for the public, for example in the Acts of Mercy scheme for the Middlesex Hospital, 1914. ${ }^{\text {iv }}$ The artist had an interest in theosophy, a spiritual and philosophical movement which grew in late nineteenth-century Britain, when varieties of the occult and Spiritualism inspired widespread popular interest (1988: 288). Theosophical ideas encouraged people to appreciate wonder and enchantment in everyday aspects of the world around us. These ideas are striking in the artist's works wherein everyday objects are uncanny and animate, while human figures are ghostly and frozen, perhaps on a higher plane of existence beyond humanity's material life, as described in theosophical tenets (1985: 168-9). These ideas encouraged types of viewing which were slow, intimate, cautious and reverential. One viewer wrote that Cayley Robinson's paintings engendered involuntary subconscious effects which could affect viewers who did not even like the paintings. The artist's techniques, with regard to mood for example, incited magical or enchanting effects. Ideas about the subconscious were becoming of heightened importance in this period. Sigmund Freud published The Interpretation of Dreams in 1899 and languages of dreams, the divided self and varied mental states were prevalent in contemporary reviews (2008, orig. 1899).

Thus Anning Bell, Gotch and Cayley Robinson had a variety of ideas about the effects of viewing art, related to the spiritual, emotions and the unconscious. I will now turn to the 'Artists and Academics' exhibition in Coventry, November 2016, and examine how the artist's ideas may help us rethink the relationships between scholarship, art and the public at this event.

\section{The 'Artists and Academics' Exhibition}

This exhibition was organised by sociologist Dr Emma Parfitt, an Early Career Fellow at the Institute of Advanced Study, Warwick. Emma created the event in support of the Coventry City of Culture 2017 bid. The exhibition was held at the Black Box, Fargo Creative Village, Coventry, Saturday 26 November 2016. Artists using varied media had worked with doctoral students at the University of Warwick whose work inspired them. The one-day event exhibited the final artistic creations resulting from these connections. Large panels of information about the PhD research which inspired the artworks were displayed adjacent to artworks. A number of artists were also present, adding another dimension to viewing and interpretation. There was a voting wall where 
viewers could add sticky dots to their favourite artist's name and post-it notes were available for feedback comments.

I visited the exhibition with a local artist, Holly Dawes. We both had varying responses to the exhibits and discussed a number of areas which link both with Dr Parfitt's aims for the exhibition and the ideas of the artists Anning Bell, Gotch and Cayley Robinson.

\section{Art as a Communicator}

One of Dr Parfitt's aims for the exhibition was to make research and ideas from the academic world more accessible, understandable and relevant. Unfortunately, there is only space here to explore a limited number of artworks from the range on display, across varied media. We found that the artworks were able to communicate a wide spectrum of research with ease, ranging from the abstract engineering concepts, to history, film, television and subjects relating to health and illness. As scholarly ideas were exported successfully from the University to an accessible, relaxed environment, academic research immediately became more integrated with the local community. Holly Dawes noted that in Jenney Egerton's 'You Have No Power Over Me' (See Article Cover Image), popular culture references could draw viewers in to the ideas. Comments from the public included: 'made research look fun, made me want to do some myself!' These comments echo views by Anning Bell, Gotch and Cayley Robinson regarding the power of art as a communicator (1918: 18).

\section{Art and Unconscious Effects}

Furthermore, we found evidence at the exhibition of art's effect on viewers through intangible and unconscious means. Art could inspire physical and emotional responses such as our differing response to jewellery items created by Libby Ward using animal hair (Fig. 1). Ward's work linked with the research of Laura Tucker in Sociology concerning the relationships ex-military personnel have with animals they share their lives with. Ward has described that her process of creation starts with textures to make unusual surfaces, seeking 'strange existing materials that I have found or altered.' Through her methods, privileging manipulation of the surface, Ward considered the therapeutic value of physical connections with beloved animals. During our visit, these artworks drew our attention as we both had visceral reactions to the pieces. While we debated the meaning and scholarly ideas it related to, our spontaneous responses were personal, instinctive and quite separate 
from our analytical discussion. These memorable effects are similar to the subconscious effects attributed to Cayley Robinson's works.

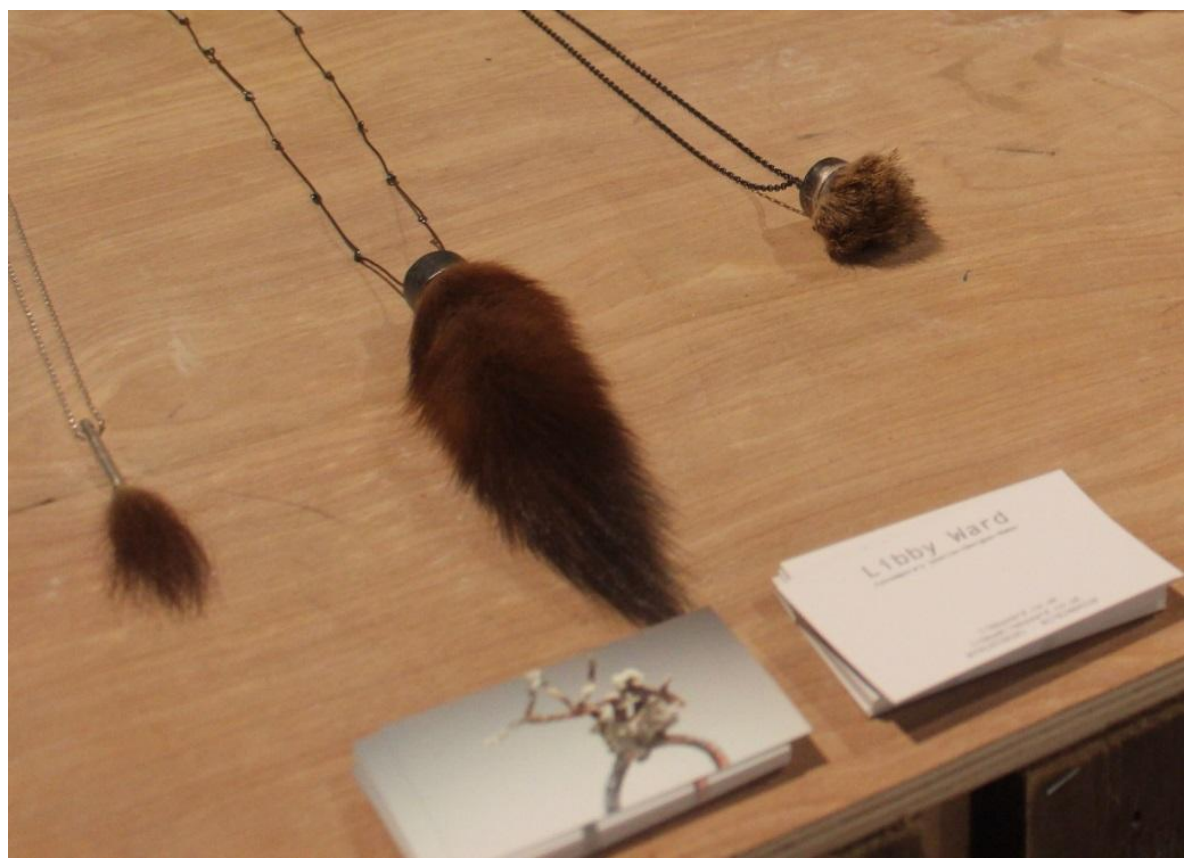

1. Libby Ward, Fur Collection, inspired by the research of Laura Tucker, Sociology: www.libbyward.co.uk. Photograph from author's collection.

I found that further spiritual effects could be experienced through the resin jewellery works by Alice Bignami Todd, which had resulted from her collaboration with Alice Byrne, Department of History (Fig. 2). Pendants displayed incorporated imagery of the myth of St. George and the dragon. Myth, symbolism and the construction of identities in the past and present are particularly relevant to Coventry with its well-known legend of Godiva featured in the statue in the city centre and paintings exhibited at the Herbert Art Gallery (Selley, 2009). Todd has described with regard to her method that embedding objects in resin gives the 'impression that they are floating in space or suspended in time.' This language evokes the mystical and enchanting possibilities of such artworks. This jewellery can be held, worn and connected with physically, enhancing the intimate connection and promising iconic value through association with mythology. A similar pendant was made from a Cayley Robinson painting in the early twentieth century (2016: 261). The use of myths, legends and imaginative subjects and the possibilities of artworks to project these ideas through spiritual potency, resonance and enchantment were embraced by Anning Bell, Gotch and Cayley Robinson as well as many other artists of the modern period (1989). 


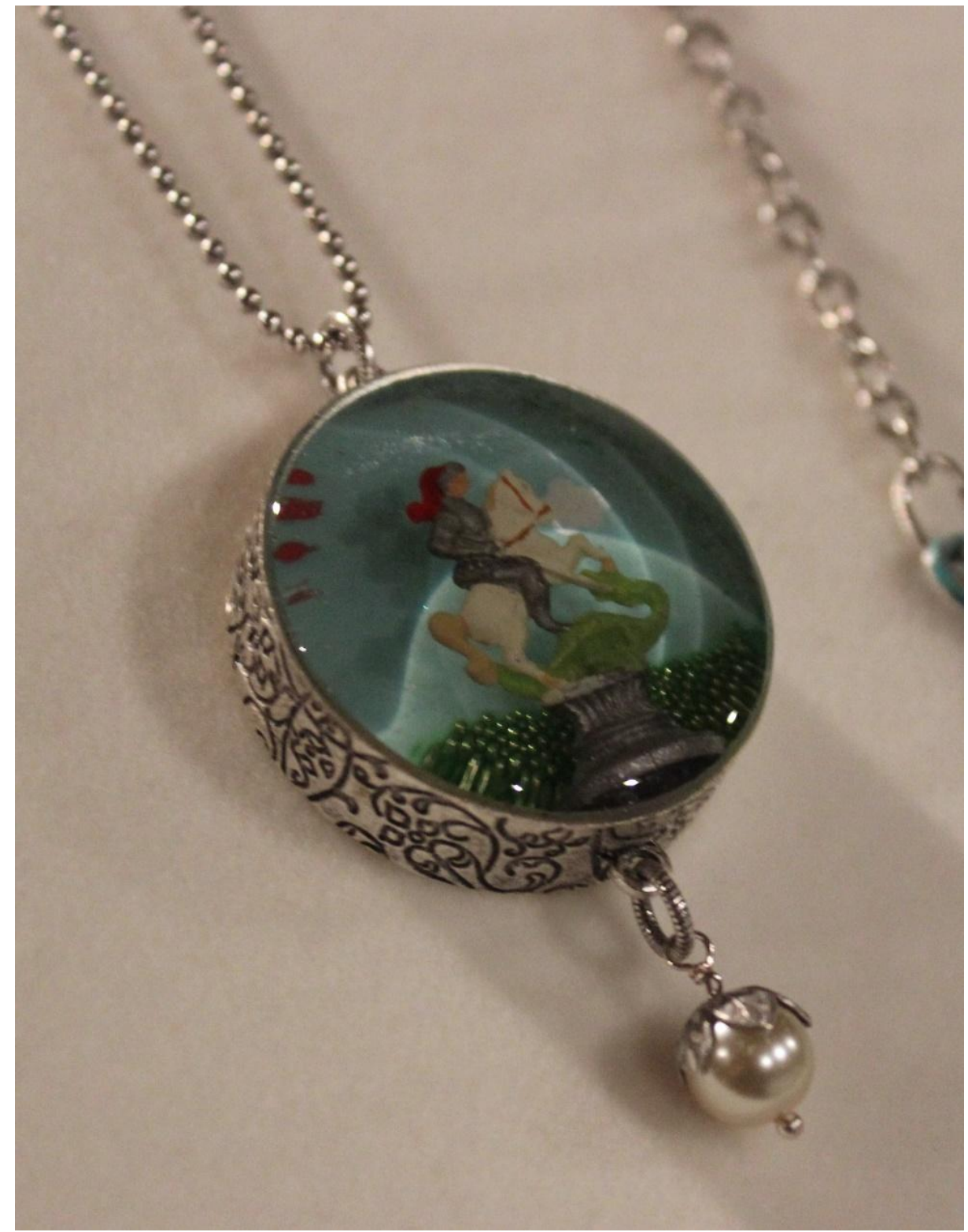

2. Alice Bignami Todd, Resin Jewellery featuring St. George the Dragon: www.resinjewelsbyalice.etsy.com Inspired by the research of Alice Byrne, History Department. Photograph from author's collection.

Pertinently, such intangible, magical effects may usually be gained by viewing artworks in public space, rather than in reproduction in books or digital media. An historical example of this is the case of close friends William Morris and Edward Burne-Jones who were both inspired to become artists by undertaking a tour of churches in Europe after they finished their degrees at Oxford. The act of touring and viewing these buildings overawed the young men, who felt emotional and spiritual elevation through art, architecture and associated symbolism. These effects had not been gained through their conscientious reading and study beforehand (2010). The spiritual in art remained a key feature of 
modernist artworks, expounded for example by Wassily Kandinsky in his essay 'On the Spiritual in Art', 1907 (1907).

Though the definition of 'spiritual' can be a very personal construct by artist or viewer, varying ideas about such effects nevertheless continue to inform art displayed today. Viewers may be equally moved emotionally or spiritually by an abstract contemporary installation in the Turbine Hall of Tate Modern as they might be by Pre-Raphaelite paintings in the Birmingham Museum and Art Gallery or the John Piper windows in Coventry Cathedral, which have more specifically religious themes. Art with spiritual themes continues to infuse new exhibitions at, for example, the Tate and the Watts Gallery. The stained glass works by Brian Dickinson (Fig. 3) and the sculptural form by Arty-Folks (Fig. 4) in this exhibition reminded me that the experience of viewing in public space can evoke a wealth of emotional responses, which cannot be gained by looking at photographs.

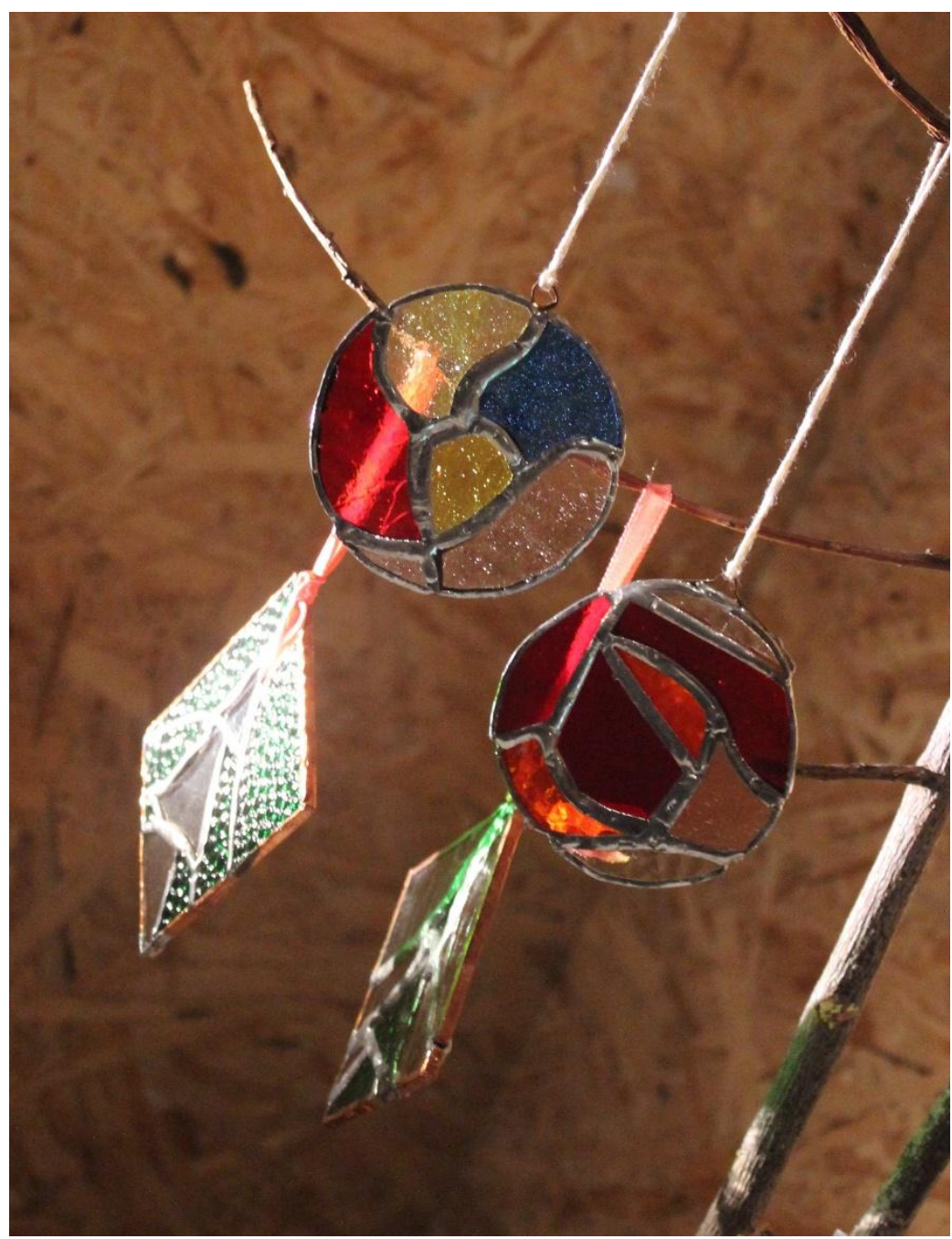

3. Stained Glass Objects by Brian Dickinson, www.dolittleglass.co.uk Dickinson also exhibited work inspired by the research of Robert EspleyJones, Department of Engineering. Photograph from author's collection. 


\section{Art and Meaning: Tensions and Possibilities}

I attended the exhibition as an academic and it was refreshing to gain an artist's perspective on the event and artworks. The responses of Holly Dawes considered the processes of commissioning and making artworks more than mine did. Dawes asked: 'How had the artworks come about and how much had the researcher guided the form of the final artwork?' Scholarly ideas presented next to artworks could provide a level of ownership for the viewer greater than the more closed form of an interpretative panel or academic article. The juxtapositions could allow an artist to consider how they might have responded to similar ideas, asking: 'What would I have done?' Dawes noted that this combination could be more inspirational than artworks alone, a sentiment which supports the value of academic ideas placed in conversation with artworks.

However, at the same time, the combination of academic ideas and artworks led to some tensions within viewing processes. Dawes discussed the idea of progression from research to artwork, asking: 'What was the connection with the research?' Pondering this could then delimit interpretation and responses as a translation was sought. Another post-it comment left by a member of the public read: 'interesting we don't have the language to describe our thoughts.' A desire for knowledge of the research ideas was evidenced by visitors reading the provided information panels. However, this was experienced in tension with the emotional and spontaneous responses artworks can inspire through visual and material qualities alone. Thus while situating ideas next to artworks could offer the viewer potentially the most inspirational form of engagement, this format could lead to concerns with the right reading or response, or with finding a linear progression from idea to artwork. These issues echo historic concerns of artistic modernism: the tensions between art and life, the desire to privilege formal elements of painting and the difficult relationships this could create with the viewing public. ${ }^{v}$

\section{Concluding Thoughts}

Combining my scholarship with a review of the exhibition for the local community has led to several concluding thoughts. Firstly, this discussion has engaged with a series of apparent dichotomies: artists and academia, intellectual ideas and making art, the conscious and unconscious, knowledge and emotion, scholarly discipline and a 'free' response to artworks. However, perhaps these need not be such oppositional 
constructs. This article has arisen from my Early Career Fellowship with the Institute of Advanced Study and the productive inter-disciplinary environment this has provided. Inter-disciplinary work also seeks to situate itself across or between the academic and the public, forms of formal and informal knowledge, challenging and amending those boundaries and orthodoxies. Such collaborations also result in contradictions but these can incite productive thinking and questioning, bringing together the perspectives of academics, artists and the public. Indeed, the complexities experienced in these processes encapsulate the simultaneous challenges and rewards of public engagement which may reanimate scholarly discourse in exciting and unforeseen ways.

Secondly, regardless of era, type or location of artworks the exhibition strengthened the idea that to connect with art in front of you can be a spiritual and affective experience. Ideas about scholarship can be equally affective and inspiring, but in this example, they gained significant power from the emotional resonances of art. This notion remains as critical to many artists today as it was to Anning Bell, Gotch and Cayley Robinson. Such an exhibition may enable the public to think differently about scholarly ideas since they are communicated through more democratic and universal acts of viewing; academia may thus commandeer the powers of art to impact the unconscious as well as the conscious mind.

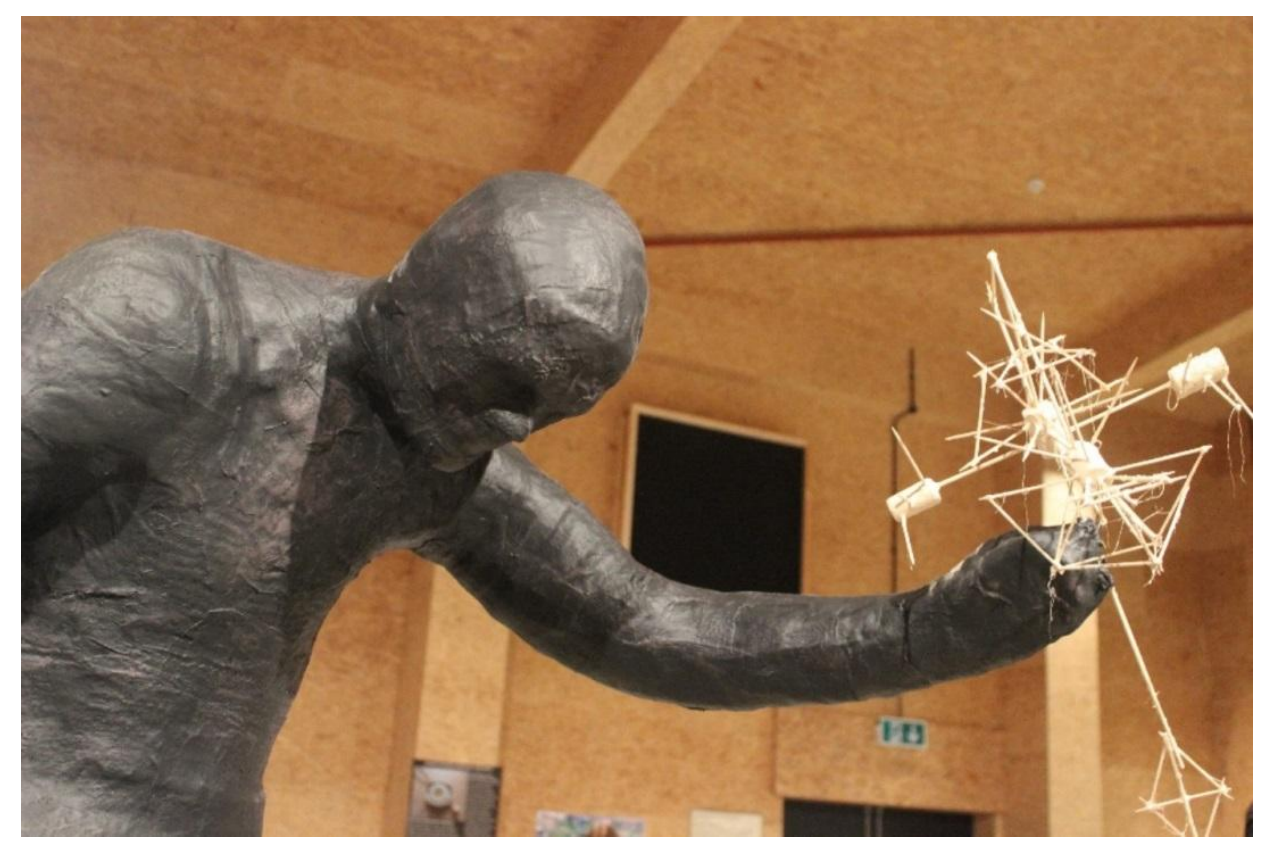

4. 'Twixt Nature \& Nurture,' Mixed media installation by Therapeutic Art Group Arty-Folks: http://arty-folks.co.uk/wp/. Inspired by the research of Rebecca Noble, Centre for History of Medicine. Photograph from author's collection. 
My time as an Early Career Fellow has allowed me to develop the Enchanted Community collaborative art project, funded by the Institute of Advanced Study, University of Warwick. The project website is: http://warwick.ac.uk/enchantedcommunity. The project allows me to develop my methodological considerations of best practice in academia and public engagement through another collaboration: between art education and the making of community art.

\section{Acknowledgements}

I am grateful to the Institute of Advanced Study, University of Warwick for funding my fellowship, which has inspired this article and funded a related community project. The 'Artists and Academics Exhibition' has been funded by the generosity of Warwick alumni, the Institute of Advanced Study and the Department of Sociology.

I would also like to thank Dr Emma Parfitt for allowing me to review her exhibition, and Holly Dawes for attending the exhibition with me.

\section{List of Illustrations}

1. Libby Ward, Fur Collection, inspired by the research of Laura Tucker, Sociology: www.libbyward.co.uk. Photograph from author's collection.

2. Alice Bignami Todd, Resin Jewellery featuring St. George the Dragon: www.resinjewelsbyalice.etsy.com Inspired by the research of Alice Byrne, History Department. Photograph from author's collection.

3. Brian Dickinson, stained glass objects, www.dolittleglass.co.uk. Dickinson also exhibited work inspired by the research of Robert EspleyJones, Department of Engineering. Photograph from author's collection.

4. Arty-Folks, Therapeutic Art Group, 'Twixt Nature \& Nurture,' Mixed media installation: http://arty-folks.co.uk/wp/. Inspired by the research of Rebecca Noble, Centre for History of Medicine. Photograph from author's collection. 
'The material for this section draws from Eden, Alice, (2016), 'Women, representation and the spiritual in the paintings of Thomas Cooper Gotch, Robert Anning Bell and Frederick Cayley Robinson', unpublished PhD thesis, University of Warwick.

ii The issues of a broader definition of cultural modernism are explored in current journals such as Modernist Cultures (Edinburgh University Press) and Modernism/modernity (The John Hopkins University Press).

iii Thomas Cooper Gotch, 'Phases of Art: Present', (London, 19 April, 1898), 'Phases of Art: Past' (London, 26 April, 1898), 'Revolution in Art', (London, 1919). These lectures are unpublished and transcripts are held in the Tate Archive, London.

iv These are now installed in the Wellcome Trust, London, and available for the public to view in the library.

${ }^{v}$ I owe this idea to Daniel Moore. This theme will be the subject of his forthcoming book: British Modernism and Public Taste, (OUP).

\section{References}

\section{Unpublished:}

Eden, Alice, (2016), 'Women, representation and the spiritual in the paintings of Thomas Cooper Gotch, Robert Anning Bell and Frederick Cayley Robinson', unpublished PhD thesis, University of Warwick Gotch, Thomas Cooper, (1919), 'Revolution in Art', transcript of lecture, Tate Archive, London: TGA 9019/2/6/37-38

Gotch, Thomas Cooper, 'Phases of Art: Past', (19 ${ }^{\text {th }}$ April, 1898), transcript of lecture, Tate Archive, London: TGA 9019/2/6/2-12, TGA 9019/2/6:

Writings and Papers

Gotch, Thomas Cooper, 'Phases of Art: Present,' $\left(26^{\text {th }}\right.$ April, 1898), transcript of lecture, Tate Archive, London: TGA 9019/2/6/2-12, TGA 9019/2/6: Writings and Papers

Moore, Daniel, (Forthcoming), British Modernism and Public Taste: OUP

\section{Primary:}

Bell, Robert Anning, (1921), 'Take Art to the Public: Professor Bell's Views', The Times, 18 March, 1921, p.11

Freud, Sigmund, (2008, orig. 1899), The Interpretation of Dreams, translated by Joyce Crick, Oxford: Oxford University Press 
Hind, C. Lewis, (1904), 'Ethical Art and Mr F. Cayley Robinson', The Studio, 31, 235- 241

\section{Secondary:}

Borzello, Frances, (1987), Civilising Caliban: The Misuse of Art 1875-1980, London: Routledge \& Kegan Paul

Brantlinger, Patrick, (1988), Rule of Darkness: British Literature and Imperialism, 1830-1914, Ithaca and London: Cornell University Press

Christian, John, (ed), (1989), The Last Romantics: The Romantic Tradition in British Art: Burne-Jones to Stanley Spencer, London: Lund Humphries in association with the Barbican Art Gallery, [exhibition catalogue, Barbican Art Gallery, London, 9 Feb - 9 April 1989]

Eden, Alice, (2012), 'Robert Anning Bell in Liverpool: Arts and Crafts and the Creation of a Civic Artistic Culture, 1895-9', The Burlington Magazine, Volume CLIV, Number 1310, 345-350

Facos, Michelle, (2009), Symbolist Art in Context, Berkeley, Los Angeles, London: University of California Press

Kandinsky, Wassily, (2006, orig. 1907), Concerning the Spiritual in Art, translated by Michael T.H. Sadler, London: Tate

MacCarthy, Fiona, (2010), William Morris: A Life for Our Time, London: Faber and Faber

Oppenheim, Janet, (1985), The Other World: Spiritualism and Psychical Research in England 1850-1914, Cambridge: Cambridge University Press

Selley, Clare, (2009), Coventry: Hidden in Plain Sight, Breedon Books Publishing, Derby

To cite this article:

Eden, A. (2017). Art, Scholarship, Community: Experiences of Viewing. Exchanges: The Warwick Research Journal, 4(2), 232-243. Retrieved from: http://exchanges.warwick.ac.uk/index.php/exchanges/article/view/158 